\title{
THE INFLUENCE OF STEEL SLAG WITH VARIABLE PARTICLE SIZE DISTRIBUTION ON THE WORKABILITY AND MECHANICAL PROPERTIES OF CONCRETE
}

\author{
JUN ZANG*, "WEIFENG LI*,**, ${ }^{*}$ XIAODONG SHEN*,** \\ *College of Materials Science and Engineering, Nanjing Tech University, \\ Nanjing 210009, China \\ **State Key Laboratory of Materials-Oriented Chemical Engineering, Nanjing Tech University, \\ Nanjing 210009, China \\ "E-mail: yc982@126.com (W. L.); xdshen@njtech.edu.cn (X. S.)
}

Submitted August 25, 2018; accepted November 9, 2018

\begin{abstract}
Keywords: Concrete, Steel slag, Particle size, Workability, Compressive strength
The present research investigated the influence of steel slag (SS) with variable particle size on the workability and mechanical properties of concrete. Different SS size ranges (0-15 $\mu \mathrm{m}, 15-30 \mu \mathrm{m}, 30-45 \mu \mathrm{m}$ and 45-80 $\mu \mathrm{m})$ were obtained by sieving and then were characterised by a laser particle size analyser and a scanning electron microscope (SEM). The slump, compressive strength, pore structures and thermal analysis were used to evaluate the effect of the SS particle size on cement and concrete properties. The experimental results showed that finer SS (0-15 $\mu \mathrm{m}$ and 15-30 $\mu \mathrm{m})$ resulted in negative effects on the workability, while 30-45 $\mu \mathrm{m}$ and 45-80 $\mu \mathrm{m}$ SS particles presented completely opposite results. Both of these effects were more apparent as the steel slag replacement ratio was increased up to $30 \mathrm{wt}$. \%. Concrete samples with 0-15 $\mu \mathrm{m}$ and 45-80 $\mu \mathrm{m}$ SS particles presented comparable 7-and 28-day compressive strength to the control concrete when their replacement ratios were less than $10 \mathrm{wt} . \%$. Moreover, the concrete samples with 45-80 $\mathrm{m}$ SS particles at $5 \%$ dosage developed the highest compressive strengths at 7 and 28 days, which were $2 \%$ and $5 \%$ higher than the control sample, respectively. The pore structure results indicated that a composition of $5 \%$ 45-80 $\mu \mathrm{m}$ SS particles was advantageous for refining the pore structures of cement paste, further contributing to the 28-day compressive strength development of concrete.
\end{abstract}

\section{INTRODUCTION}

Concrete has been an irreplaceable man-made material in the field of engineering since its creation [1], and its annual production exceeds 20 billion tonnes [2]. A large amount of cement, an essential ingredient of concrete, is also produced to cast concrete. It is estimated that the cement industry accounts for approximately 7 $\%$ of worldwide $\mathrm{CO}_{2}$ emissions alone [3], resulting in serious environmental problems. Thus, it is necessary for the cement and concrete industry to seek alternative and sustainable "eco-friendly building materials" that perform similarly to or even better than conventional materials to achieve social sustainable development.

Steel slag (SS) is a by-product of steel manufacturing [4], and a large quantity of SS is annually produced around the world. It is estimated that the annual accumulation rate of SS in China is nearly 100 million tonnes [5], and the most common SS disposal method is disposing it in a landfill. However, this direct improper disposal without any utilisation results in many problems in terms of disposal costs, land occupation and environmental contamination. Because of its certain cementitious properties $[6,7]$, SS has gradually become an alternative additive to partially replace cement in paste, and mortar and concrete in construction applications. It is also often used as a fine or coarse aggregate in concrete production [8-14]. In addition to the economic and ecological benefits, it can also bring many engineering benefits.

Extensive research has been devoted to the properties of mortars or concretes with SS incorporated, and the results indicate that SS is advantageous in terms of the mechanical strength and durability of the hardened mortars and concretes [13-21]. Tsakiridis et al. [8] found that SS cement consisting of $10.5 \%$ SS in the raw meal showed comparable properties to the reference sample in terms of the setting time and compressive strength. In the works of Yang et al. [16], the addition of $20 \%$ $\mathrm{SS}$ in magnesium potassium phosphate cement (MKPC) resulted in a $5 \%, 30 \%$ and $8 \%$ higher compressive strength than in the control sample at $5 \mathrm{~h}, 1$ day and 60 days, respectively. Compared to the control sample, the 28- and 60-day shrinkage also decreased approximately $57 \%$ and $41 \%$, respectively. Additional studies also indicate that SS can help to improve other properties of concrete, such as fire resistance [12], sulphate attack resistance [14] and abrasion resistance [9]. 
Previous studies presented the effectiveness of using $\mathrm{SS}$ as an additive in the cement and concrete industry. However, many problems still need to be further solved before its application can be realised. Many studies are limited to various properties of cementitious materials that incorporate SS, while limited research is focused on investigating the influence of SS with variable particle size distribution from the same SS source on the properties of the cement or concrete. Wang et al. [20] investigated the effects of a fine steel slag (FSS) $(<20 \mu \mathrm{m})$ and a coarse steel slag $(\mathrm{CSS})(>20 \mu \mathrm{m})$ on the properties of the cement and concrete. The authors found that an FSS within a $20 \%$ replacement level showed negligible influences on the compressive strength, drying shrinkage and permeability of concrete at 28 days. However, the previous research is far from satisfactory. Since SS contains many glass phases (amorphous phases), Idir et al. [22] claimed that a glass powder with a size smaller than $80 \mu \mathrm{m}$ was pozzolanically reactive. Therefore, the effects that the designed size ranges, which are smaller than $80 \mu \mathrm{m}$, have on the properties of the cementitious materials should also be noted.

Under such a background, the first objective of this work was to obtain and preliminary characterise different size ranges of ground SS particles (less than

Table 1. The chemical compositions and physical properties of the cement and steel slag.

\begin{tabular}{lcc}
\hline Chemical composition (\%) & Cement & Steel slag \\
\hline $\mathrm{CaO}$ & 63.06 & 46.94 \\
$\mathrm{SiO}_{2}$ & 20.51 & 14.32 \\
$\mathrm{Al}_{2} \mathrm{O}_{3}$ & 5.91 & 4.92 \\
$\mathrm{Fe}_{2} \mathrm{O}_{3}$ & 4.26 & 22.41 \\
$\mathrm{MgO}$ & 2.68 & 10.23 \\
$\mathrm{SO}_{3}$ & 2.06 & 0.27 \\
Loss on ignition & 1.52 & 0.91 \\
\hline & \multicolumn{2}{c}{ Physical property } \\
\cline { 2 - 3 } Specific gravity $\left(\mathrm{g} \cdot \mathrm{cm}^{-3}\right)$ & 3.05 & 3.35 \\
$\mathrm{D}_{50}(\mu \mathrm{m})$ & 20.1 & - \\
\hline
\end{tabular}

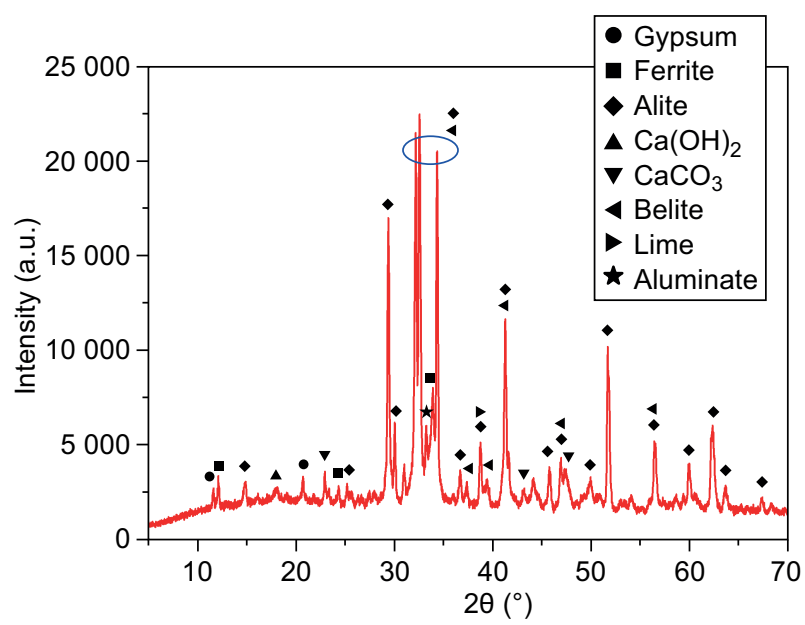

Figure 1. The mineralogical composition of the cement.
$15 \mu \mathrm{m}, 15-30 \mu \mathrm{m}, 30-45 \mu \mathrm{m}$ and 45-80 $\mu \mathrm{m}$ ) from the same SS source. The second objective was to assess the effects of these four fractions of steel slag on the workability and compressive strength of the concrete. Then, some important hydration characteristics of the selected SS-cement binary system were also analysed for the pore structures and thermal analysis. The findings of this paper will help to improve the utilisation ratio of SS in the cement or concrete industries, and they serve to effectively establish a low-carbon economy.

\section{EXPERIMENTAL}

\section{Materials}

Type II-52.5 Portland cement from China United Cement Huaihai Co., Ltd. was used in this study. The steel slag used in this investigation was steel converter slag, produced by the heat-stewed method. The chemical compositions of the raw materials summarised in Table 1 were determined by X-ray fluorescence (XRF, ARL ADVANT'XP, ThermoFisher Scientific, USA). Their mineralogical compositions were also determined by X-ray diffraction (XRD, Rigaku SmartLab 3000A, Japan), as shown in Figure 1 and Figure 2, respectively. Tricalcium silicate $\left(\mathrm{C}_{3} \mathrm{~S}\right)$, dicalcium silicate $\left(\mathrm{C}_{2} \mathrm{~S}\right)$, tricalcium aluminate $\left(\mathrm{C}_{3} \mathrm{~A}\right)$ and ferrite $\left(\mathrm{C}_{4} \mathrm{AF}\right)$ were identified as the main crystalline phases in the cement (Figure 1), while $\mathrm{C}_{2} \mathrm{~S}$ and $\mathrm{C}_{2} \mathrm{~F}$ were present in steel slag, which potentially contributed to the cementitious property.

\section{Methods \\ Grading and characterisation of the steel slag}

To investigate the influences of different particle sizes of the SS on the fresh and mechanical properties of the concrete, the steel slag was first classified into different fractions by a negative pressure sieve (FSY-150D,

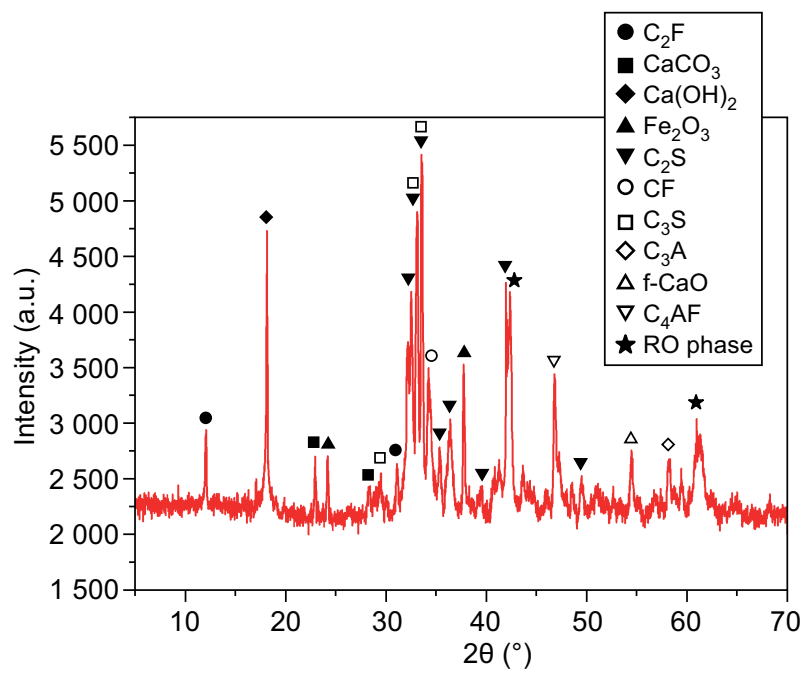

Figure 2. The mineralogical composition of the steel slag. 
SHAOXING, China): 0-15 $\mu \mathrm{m}, 15-30 \mu \mathrm{m}, 30-45 \mu \mathrm{m}$ and $45-80 \mu \mathrm{m}$, designated as S1, S2, S3 and S4, respectively. Then, the corresponding chemical compositions, mineralogical compositions, particle size distributions and microstructures of these separated SS were determined by an ARL ADVANT'XP X-ray fluorescence (XRF), a Rigaku SmartLab 3000A X-ray diffraction (XRD), a Malvern Mastersizer 2000 Particle size Analyser and an FEI Quanta FEG 450 scanning electron microscope (SEM), respectively.

\section{Preparation and characterisation of the concrete}

In this work, four fractions of steel slag were used to replace cement with various levels from 0 to $30 \%$ by volume. The details of the concrete mixtures are summarised in Table 2. The mix ID was designed by combining the abbreviation of the steel slag and the corresponding replacement level. Take SS05 as an example: it refers to a mixture with steel slag as 5\% of the total binder, where the binder $=$ cement + steel slag. As shown in Table 2, the water to binder ratio (w/b) was fixed at 0.55 for all concrete mixtures. The amounts of fine and coarse aggregates were maintained at 813 and $1077 \mathrm{~kg} \cdot \mathrm{m}^{-3}$, respectively.

The mixing procedure for all ingredients was performed in a laboratory mixer. The slump of the fresh concrete was first determined according to GB/T500802002. Then, the fresh concrete was cast into a cubic mould with a size of $100 \mathrm{~mm}$ and demoulded after 1 day. Before testing, these cubic specimens were placed in a curing room at a constant temperature of $20{ }^{\circ} \mathrm{C}$ with $100 \%$ relative humidity $(\mathrm{RH})$. The compressive strength test was performed based on GB/T50081-2002 at the ages of 7 and 28 days.

\section{Preparation and characterisation of the pastes}

This step mainly focused on investigating the hydration products and pore structures of the selective binary system consisting of the cement and SS. These selective paste samples were prepared according to the corresponding mixture proportions of the concrete, except for the exclusion of fine aggregates, coarse ag- gregates and superplasticisers. The paste samples were further tested by following the previous procedure [23]. A PoreMaster GT60 mercury intrusion porosimeter (Quantachrome, Houston, TX, USA) was used to analyse the pore structures of the samples in terms of the porosity and pore size distribution. A Mettler Toledo thermal analyser (TGA/DSC, NETZSCH, ATA409, NETZSCH, Selb, Germany) was used for the thermal analysis. The samples were heated at a rate of $10^{\circ} \mathrm{C} / \mathrm{min}$ under a nitrogen atmosphere, and the TG curves were recorded from 40 to $1000{ }^{\circ} \mathrm{C}$.

\section{RESULTS AND DISCUSSION}

\section{Characterisation of the steel slag}

The particle size distribution (PSD) results for the different fractions of the steel slag are presented in Fig. 3. The steel slag can be divided into four fractions based on the particle size: $0-15 \mu \mathrm{m}, 15-30 \mu \mathrm{m}, 30-45 \mu \mathrm{m}$ and 45-80 $\mu \mathrm{m}$. The corresponding median particle size $\left(\mathrm{d}_{50}\right)$ of each fraction was $7.3,22.5,33.5$ and $66.2 \mu \mathrm{m}$, respectively. Moreover, it can be seen from Figure 3 that the cumulative particle sizes within these four ranges are $99.9 \%, 89.4 \%, 97.7 \%$ and $89.7 \%$, respectively.

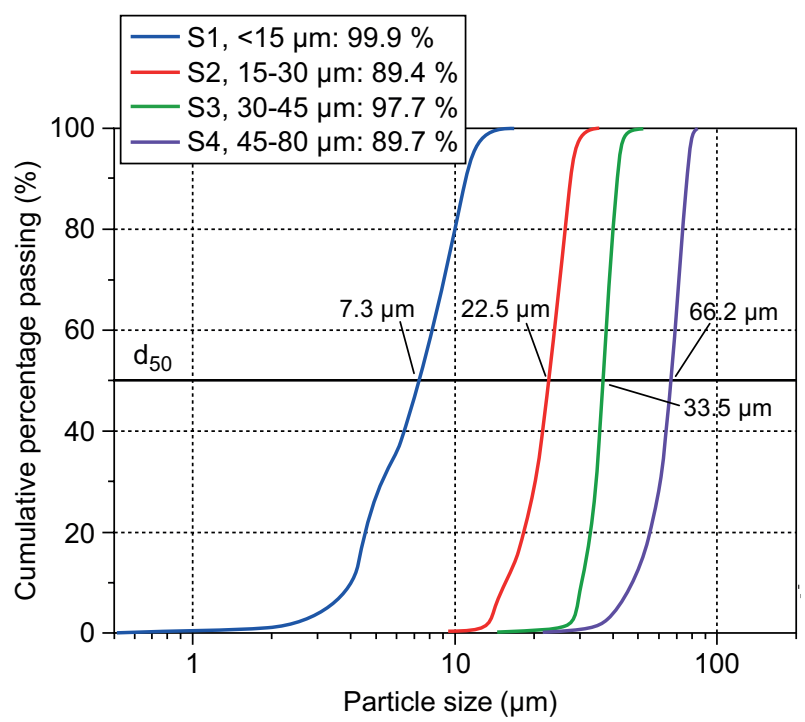

Figure 3. The particle size distributions of the different fractions of the steel slag.

Table 2. The mixture proportions of the concrete $\left(\mathrm{kg} \cdot \mathrm{m}^{-3}\right)$.

\begin{tabular}{ccccccc}
\hline Mix ID & Cement & Steel slag & Fine aggregate & Coarse aggregate & Water & Superplasticiser \\
\hline SS0 & 310 & 0 & 813 & 1077 & 170 & 3.4 \\
SS05 & 295 & 17 & 813 & 1077 & 170 & 3.4 \\
SS10 & 279 & 34 & 813 & 1077 & 170 & 3.4 \\
SS15 & 264 & 51 & 813 & 1077 & 170 & 3.4 \\
SS20 & 248 & 68 & 813 & 1077 & 170 & 3.4 \\
SS25 & 233 & 85 & 813 & 1077 & 170 & 3.4 \\
SS30 & 217 & 102 & & & 170 & 3.4 \\
\hline
\end{tabular}


Figure 4 shows the morphology results for S1, S2, S3 and S4 obtained by SEM. As seen in Figure 4, the steel slag particles are irregular in shape. S1 has small particles with smooth surfaces. However, on the contrary, when the particles' size increased, the steel slag particles presented rougher surfaces, especially for S4. Moreover, some adhesion of the finer particles of the steel slag on the coarser particles can also be observed.

From the particle size distribution curves and the morphologies of the steel slag, the separation effect of the granularity interval for the steel slag is generally ideal. However, some overlap of the particle size range also existed, which can be attributed to the adsorption of the finer particles on the coarser steel slag particles (shown in Figure 4). Additionally, an unstable pressure and the operation during the screening process might also create slightly larger particles through the smaller mesh.

Table 3 provides the chemical compositions of the classified steel slag (S1, S2, S3 and S4). It can be clearly seen from Table 3 that the $\mathrm{CaO}, \mathrm{Al}_{2} \mathrm{O}_{3}$ and $\mathrm{SO}_{3}$ contents in these classified steel slags were slightly lower than those in the un-classified steel slag, while the $\mathrm{SiO}_{2}, \mathrm{Fe}_{2} \mathrm{O}_{3}$ and $\mathrm{MgO}$ contents were higher than

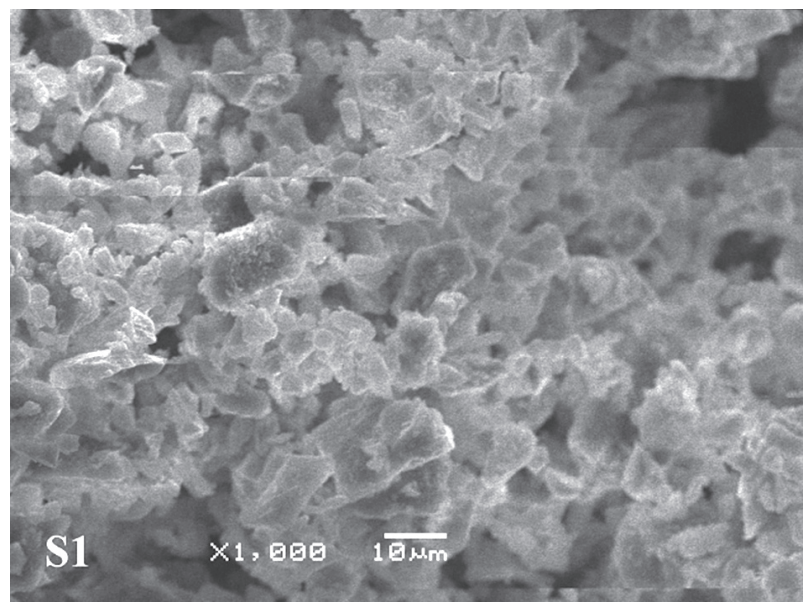

a)

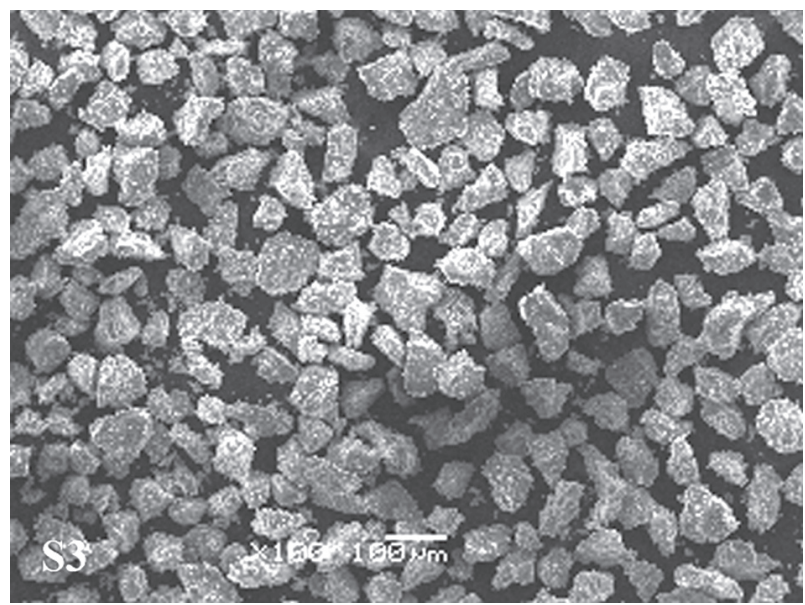

c) those in the un-classified steel slag. Figure 5 illustrates the XRD patterns of S1, S2, S3 and S4. Compared with the un-classified steel slag, the main mineralogical compositions in these classified steel slags did not show any significant changes.

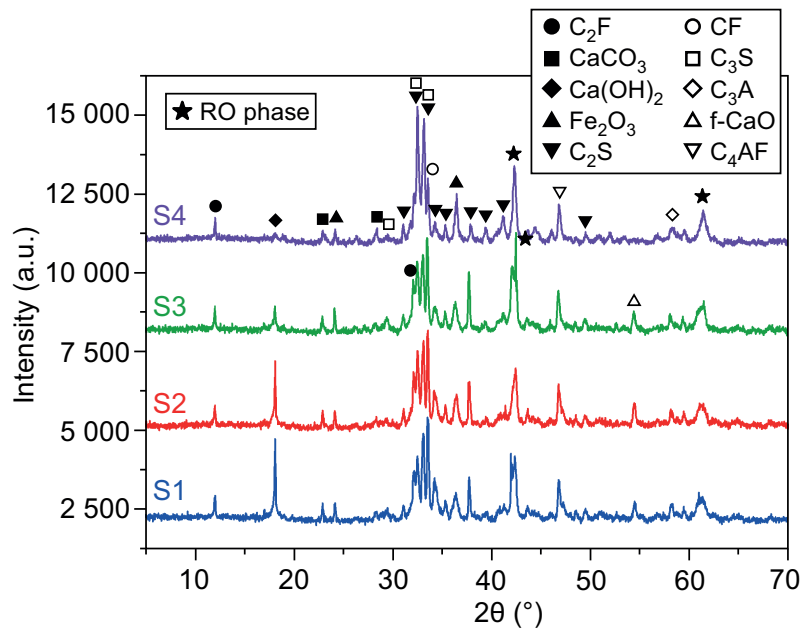

Figure 5. The mineralogical composition of the classified steel slag.

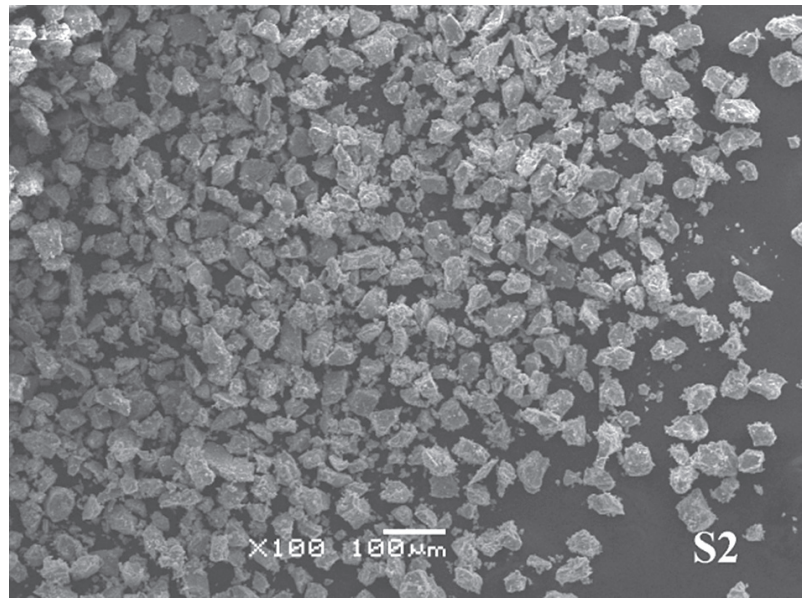

b)

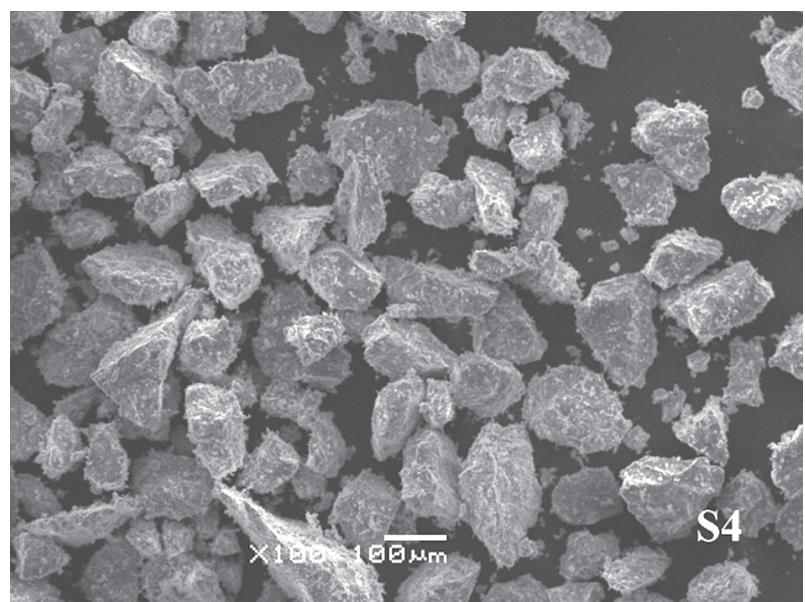

d)

Figure 4. The morphologies of the steel slag (S1: 0-15 $\mu \mathrm{m}$; S2: 15-30 $\mu \mathrm{m} ; \mathrm{S} 3: 30-45 \mu \mathrm{m} ; \mathrm{S} 4: 45-80 \mu \mathrm{m}$ ). 
Table 3. The chemical compositions of the classified steel slag.

\begin{tabular}{lrrrr}
\hline $\begin{array}{l}\text { Chemical } \\
\text { composition (\%) }\end{array}$ & $\mathrm{S} 1$ & $\mathrm{~S} 2$ & $\mathrm{~S} 3$ & $\mathrm{~S} 4$ \\
\hline $\mathrm{CaO}$ & 44.79 & 44.66 & 44.39 & 43.6 \\
$\mathrm{SiO}_{2}$ & 14.64 & 14.76 & 15.24 & 15.63 \\
$\mathrm{Al}_{2} \mathrm{O}_{3}$ & 2.78 & 2.89 & 2.84 & 2.97 \\
$\mathrm{Fe}_{2} \mathrm{O}_{3}$ & 22.99 & 23.37 & 23.4 & 22.84 \\
$\mathrm{MgO}$ & 11.31 & 11.28 & 11.06 & 12.01 \\
$\mathrm{SO}_{3}$ & 0.09 & 0.08 & 0.09 & 0.05 \\
Loss on ignition & 3.4 & 2.96 & 2.98 & 2.9 \\
\hline
\end{tabular}

The effects of the steel slag on the properties of the concrete

\section{Slump}

Workability is an important performance characteristic of the concrete, which largely determines the difficulty of the concrete construction and the compactness of the concrete after vibration. Figure 6 depicts the effect of the steel slag with the different particle sizes on the concrete slump. It can be seen that the slump changed remarkably when the steel slag was incorporated.

In series $\mathrm{S} 1$, the slump values of the concrete with S1 of $5 \%, 10 \%, 15 \%, 20 \%, 25 \%$ and $30 \%$ were 189 , 179, 169, 159, 150 and $145 \mathrm{~mm}$ (as shown in Table 4), respectively, a decrease of $0.5 \%, 5.8 \%, 11.1 \%, 16.3 \%$,

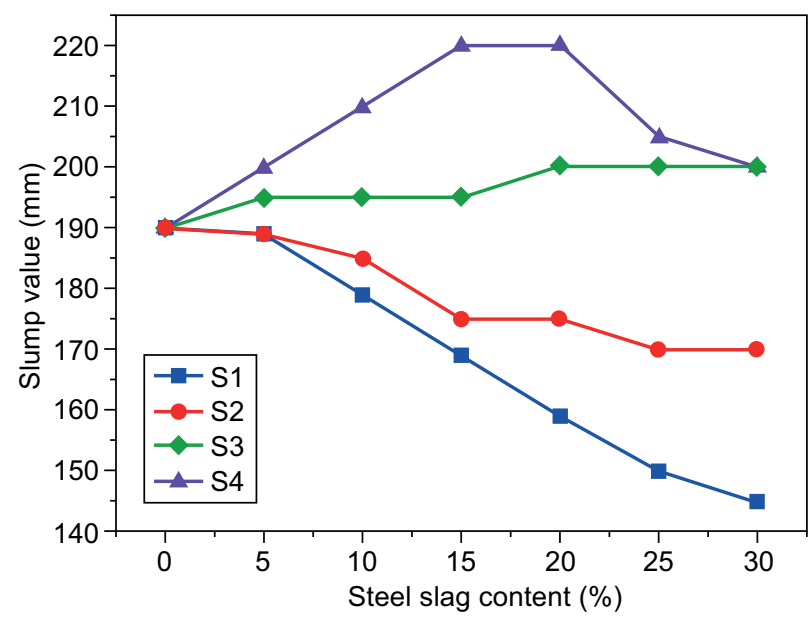

Figure 6. The influence of the steel slag on the concrete slump.
$21.1 \%$ and $23.7 \%$ compared to the control concrete, indicating that S1 significantly decreased the workability of the concrete. Considering the relatively finer particle size of S1 $\left(\mathrm{d}_{50}\right.$ of $\left.7.3 \mu \mathrm{m}\right)$ compared to that of the cement $\left(\mathrm{d}_{50}\right.$ of $\left.20.1 \mu \mathrm{m}\right)$, which results in a larger surface area, the decrease in slump can be attributed to the greater water absorption by the S1 particles and less free water to improve the workability of the concrete. A similar reduction trend in the slump can also be observed in the S2 samples, but with a different percentage reduction, and the increase in the steel slag content from $0 \%$ to $30 \%$ decreased the slump by approximately up to $24 \%$.

In contrast to $\mathrm{S} 1$ and $\mathrm{S} 2$, the concrete with $\mathrm{S} 3$ and S4 presented a higher slump than the control concrete, especially for the S4 series, indicating that better workability can be achieved. However, unlike the continuous increase of S3, the concrete slump tended to decrease when the steel slag content was over $20 \%$ for the S4 sample. When a higher percentage (over $20 \%$ ) of the steel slag was added, more water was absorbed because of the relatively rough texture of the $45-80 \mu \mathrm{m}$ SS particles. Moreover, voids between the steel slag particles or between the steel slag and the cement particles were formed because of the irregular shape [24]. Therefore, more water is needed to maintain the desired slump. Similar results can also be observed in Rehman et al.'s work [25]. Moreover, with a constant replacement level, a coarser steel slag also exhibited a better workability.

\section{The compressive strength}

The compressive strength is also an important factor to consider when examining the properties of concrete. The compressive strength developments at 7 and 28 days are shown in Figures 7 and 8, respectively.

The compressive strength of the concrete with S1 at an age of 7 days increased with the steel slag content up to $5 \%$ and then slightly decreased. Compared with the control sample, the increases were $1 \%$ and $0.3 \%$ when the steel slag at concentrations of $5 \%$ and $10 \%$ were added, respectively. This increase in strength can be attributed to the ultrafine particle size of the SS, which can effectively act as a micro-filler that fills the

Table 4. The slump and the compressive strength of the different concrete mixtures.

\begin{tabular}{|c|c|c|c|c|c|c|c|c|c|c|c|c|}
\hline \multirow{3}{*}{ Mix ID } & \multirow{2}{*}{\multicolumn{4}{|c|}{ Slump (mm) }} & \multicolumn{8}{|c|}{ Compressive strength (MPa) } \\
\hline & & & & & \multicolumn{2}{|c|}{ S1 } & \multicolumn{2}{|c|}{$\mathrm{S} 2$} & \multicolumn{2}{|c|}{ S3 } & \multicolumn{2}{|c|}{ S4 } \\
\hline & $\overline{\mathrm{S} 1}$ & $\mathrm{~S} 2$ & S3 & $\overline{\mathrm{S} 4}$ & 7 days & 28 days & 7 days & 28 days & 7 days & 28 days & 7 days & 28 days \\
\hline SS0 & 190 & 190 & 190 & 190 & 29.5 & 37.8 & 29.5 & 37.8 & 29.5 & 37.8 & 29.5 & 37.8 \\
\hline SS05 & 189 & 189 & 195 & 200 & 29.8 & 39.1 & 29.3 & 37.5 & 29.3 & 37.7 & 30.1 & 39.7 \\
\hline SS10 & 179 & 185 & 195 & 210 & 29.6 & 38.3 & 28.5 & 37.1 & 27.5 & 36.9 & 29.3 & 37.9 \\
\hline SS15 & 169 & 175 & 195 & 220 & 29.1 & 37.3 & 27.6 & 36.3 & 26.2 & 35.8 & 29 & 36.3 \\
\hline SS20 & 159 & 175 & 200 & 220 & 28.9 & 36.1 & 25.9 & 35.2 & 24.8 & 34 & 26.4 & 34.1 \\
\hline SS25 & 150 & 170 & 200 & 205 & 28.7 & 35.4 & 24.7 & 33.9 & 23.6 & 32.4 & 23.5 & 32.3 \\
\hline SS30 & 145 & 170 & 200 & 200 & 28.5 & 33.7 & 23.8 & 32.1 & 22.8 & 30.9 & 22.1 & 30.4 \\
\hline
\end{tabular}


voids between the cement particles, thus causing the microstructure to have more impact and increasing the compressive strength to some degree. However, the decreases were $1.4 \%, 2 \%, 2.7 \%$ and $3.3 \%$ for the concrete containing $15 \%, 20 \%, 25 \%$ and $30 \%$ steel slag, respectively. Because of the low content of the cement in these samples (70-85 wt. \%), a sufficient amount of hydrates like calcium silicate hydrate $(\mathrm{C}-\mathrm{S}-\mathrm{H})$ gels could not be produced, resulting in the lower compressive strength. Shi et al. [6] investigated the properties of a cement mortar with a superfine steel slag $\left(\mathrm{D}_{50}=5.3 \mu \mathrm{m}\right)$ and found that the compressive strength of the cement mortar continuously decreased when the replacement weight ratio of the superfine SS was above $10 \%$.

Though S2 and S3 present a slightly coarser particle size than that of the cement, their lower pozzolanic activity at an early age led to a continuous decrease of the 7-day compressive strength. It can be observed that the decrease ratio was $0.7-19.3 \%$ and $0.7-22.7 \%$ when the S2 and $\mathrm{S} 3$ contents were increased up to $30 \%$, respectively.

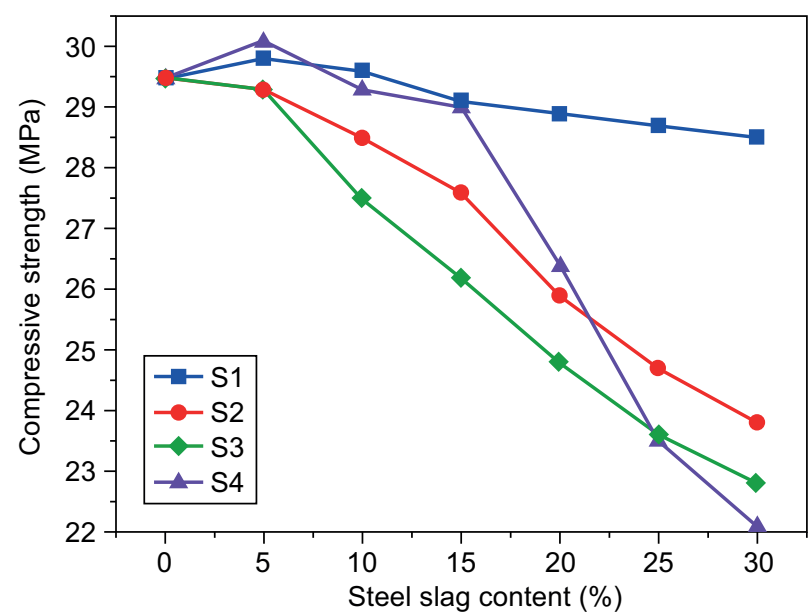

Figure 7. The 7-day compressive strength versus the steel slag content.

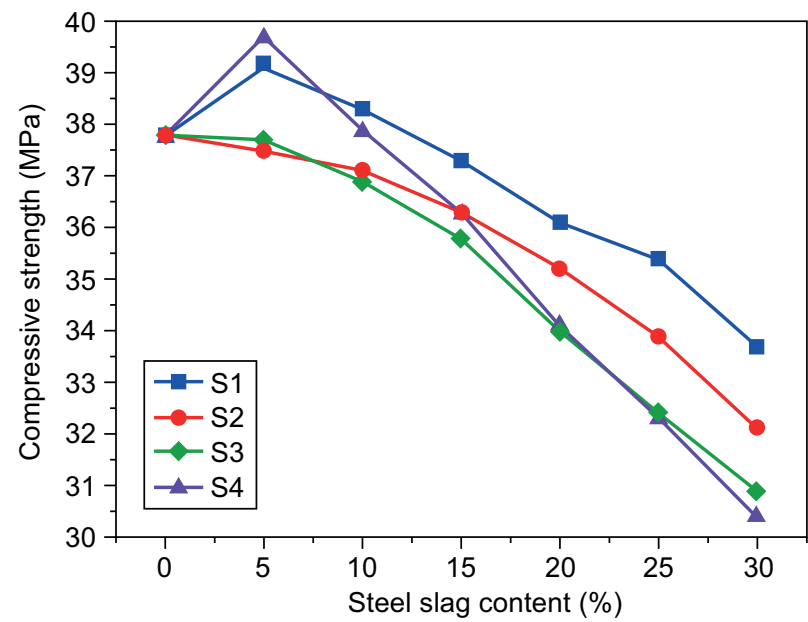

Figure 8. The 28-day compressive strength versus the steel slag content.
The concrete with S4 showed comparable compressive strength at an age of 7 days to the concrete with S1 when the steel slag was less than $15 \%$. It presented a similar compressive strength development trend to the concrete with S2 and S3 when the steel slag was over $15 \%$. The particle size range of $45-80 \mu \mathrm{m}$ is an overlapping area between cement particles and the fine aggregates, in which there is a lack of these fine particles, especially in the $45-80 \mu \mathrm{m}$ range. In this work, the cumulative sieve mass between $45-80 \mu \mathrm{m}$ in the cement and sand only accounts for $7.9 \%$ and $0.25 \%$, respectively. Therefore, S4 has a strong filling effect on the microstructure of the concrete. Thus, a less negative effect of S4 on the compressive strength development of the concrete within a replacement level lower than $10 \%$ can be observed. However, with a higher dosage (more than $10 \%$ ), the low pozzolanic activity of the steel slag dominates instead of the filling effect, resulting in the decreased compressive strength.

With the increasing curing age, the compressive strength continuously developed for each sample as the hydration went on. A similar compressive strength development trend can also be observed at 28 days. Compared with the control sample, the compressive strength increased $5 \%$ for the concrete with a $5 \%$ composition of S4, indicating faster strength development (only $2 \%$ higher than the control sample at 7 days). In contrast to the strength development at 7 days, the pozzolanic activity of the steel slag began to play an important role in contributing to the strength. Similar results were observed in the works of Zhang et al [21].

\section{The effects of the steel slag on the hydration characteristics of the concrete}

\section{Pore structure}

The pore structures of the cement pastes with or without S4 after 28 days of hydration are shown in Figure 9. Some additional information is also listed in Table 5.

As summarised in Table 5, the porosity of the control sample was $17.8 \%$ when the replacement ratio of S4 was $5 \%$. However, as the replacement ratio increased from $10 \%$ to $15 \%$, this value increased from $18.3 \%$ to $19.4 \%$ accordingly. These variations in the porosity in these samples are consistent with the compressive strength development of the corresponding samples at 28 days. That is, the lower the porosity of the paste results in a higher compressive strength of the corresponding concrete. The hardened cement paste with S4 incorporated at a concentration of $5 \%$ exhibited the lowest porosity, while the corresponding concrete samples presented the highest compressive strength of $38.9 \mathrm{MPa}, 1.9 \mathrm{MPa}$ higher than that of the control sample. A similar relationship between the porosity and the compressive strength of the system was also described in the works of Zhang et al [26]. 
Combined with the existing research, the pore structures of the samples (shown in Figure 9) used in the current work are mainly classified into three parts [27]: $<0.01 \mu \mathrm{m}$ (gel pores), 0.01-0.05 (medium capillary pores), and $>0.05$ (large capillary pores). All four samples presented differential peaks at the pore diameters within the range of $0.001-0.1 \mu \mathrm{m}$. All the samples presented similar pore size distributions. However, these curves differed greatly in detail, as summarised in Table 5. Compared with the control paste, the addition of S4 at $5 \%$ decreased the percent of the large capillary pores, while it increased the medium capillary pores. These refined effects lowered the porosity of the control sample and thus increased the compressive strength at 28 days. For the samples containing $10 \%$ and $15 \% \mathrm{~S} 4$, the opposite results can be clearly observed.

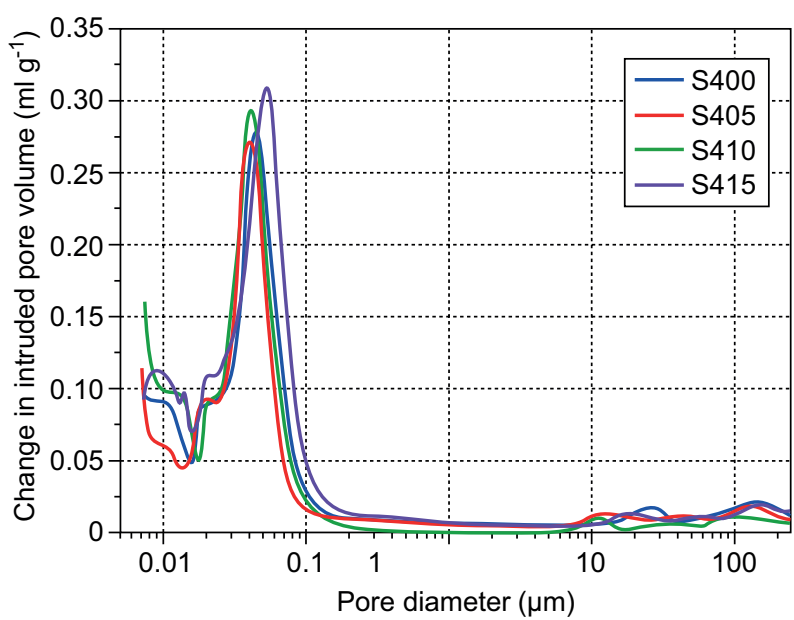

Figure 9. The change in intruded pore volume of the samples after 28 days of hydration.

Table 5. The parameters of the pore structures at 28 days.

\begin{tabular}{lcccc}
\hline \multirow{2}{*}{ Mix ID } & \multirow{2}{*}{ Porosity (\%) } & \multicolumn{3}{c}{ Pore size distribution (\%) } \\
\cline { 3 - 5 } & & $<0.01 \mu \mathrm{m}$ & $0.01-0.05 \mu \mathrm{m}$ & $>0.05 \mu \mathrm{m}$ \\
\hline S400 & 17.8 & 8.3 & 48.9 & 42.8 \\
S405 & 16.5 & 6.2 & 53.4 & 40.4 \\
S410 & 18.3 & 8.9 & 47.9 & 43.2 \\
S415 & 19.4 & 8.4 & 44.3 & 47.3 \\
\hline
\end{tabular}

\section{Thermal analysis}

Only the control and S405 samples were selected for thermal analysis, and the corresponding results are shown in Figure 10. Figure 10 presents a similar weight loss trend, but a different weight loss between the control and the S405 sample. The weight loss in the S405 sample was found to be $1.7 \%$ higher than that in the control sample, reflecting a slight promotion effect of the steel slag on the cement hydration.

Three major peaks can be clearly identified from the derivative weight curves, which correspond to the dehydration of the $\mathrm{C}-\mathrm{S}-\mathrm{H}, \mathrm{AFt}$ and $\mathrm{AFm}$ phases $\left(40-235^{\circ} \mathrm{C}\right)$
[28]; the dehydroxylation of $\mathrm{CH}\left(368-499{ }^{\circ} \mathrm{C}\right)$; and the decarbonation of $\mathrm{CaCO}_{3}\left(529-929{ }^{\circ} \mathrm{C}\right)$ [29]. Figure 10 also lists the calculated $\mathrm{CH}$ content. The $\mathrm{CH}$ content in the control sample was $11.7 \%$, while a slightly lower content $(11.6 \%)$ can be observed in the sample with $5 \% \mathrm{SS}$. According to the previous research, three possible effects contribute to the decrease in the $\mathrm{CH}$ content: The partial replacement of the cement by the steel slag decreases the relative content of the cement, which releases less $\mathrm{CH}$ during cement hydration. The effective w/c ratio also increases when the steel slag is incorporated, improving the degree of the cement hydration of some content and generating more $\mathrm{CH}$. Additionally, the steel slag presents pozzolanic activity and consumes $\mathrm{CH}$ at a later curing age. Combined with the total weight loss, the pozzolanic effect of the steel slag was believed to be the reason for the difference in the $\mathrm{CH}$ content between $\mathrm{S} 405$ and the control sample. Moreover, the steel slag consumed $\mathrm{CH}$ and produced additional $\mathrm{C}-\mathrm{S}-\mathrm{H}$, which can be helpful for compacting the microstructure of the hardened paste and developing a higher compressive strength of the concrete, as was shown in the section on the compressive strength.

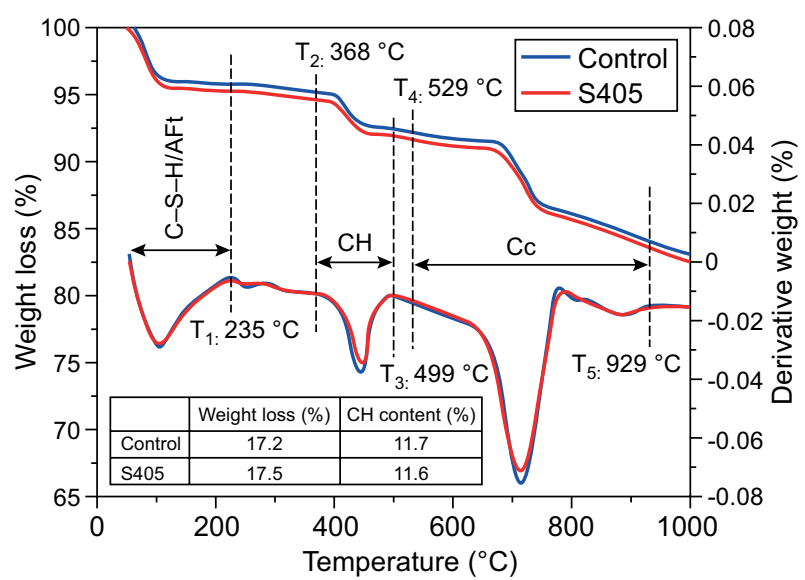

Figure 10. The thermal analysis for the $\mathrm{S} 4$ blended cement pastes hydrated for 28 days.

\section{CONCLUSIONS}

The present research preliminarily investigated the effect of variable particle size distribution of the steel slag particles from the same steel slag source on some properties of concrete and the associated cement pastes' hydration. Based on the experimental and analytical results, the following conclusions have been derived:

- The desired four size ranges of steel slag $(0-15 \mu \mathrm{m}$, 15-30 $\mu \mathrm{m}, 30-45 \mu \mathrm{m}$ and 45-80 $\mu \mathrm{m})$ were obtained.

- The steel slag with smaller sizes $(0-15 \mu \mathrm{m}$ and 15-30 $\mu \mathrm{m})$ presented a negative effect on the workability of the concrete, especially for higher replace- 
ment levels, while a positive effect was obser-ved with the addition of relatively coarser particles (30-45 $\mu \mathrm{m}$ and 45-80 $\mu \mathrm{m})$. However, the steel slag in the $45-80 \mu \mathrm{m}$ range de-creased the workability when the replacement level was over $20 \%$.

- The compressive strength of the concrete samples with the incorporated steel slag in the 15-30 $\mu \mathrm{m}$ and $30-45 \mu \mathrm{m}$ ranges continually decreased, while their replacement levels increased up to $30 \%$ at 7 and 28 days, respectively.

- In contrast to the incorporated steel slag in the 15-30 $\mu \mathrm{m}$ and 30-45 $\mu \mathrm{m}$ ranges, the steel slag particles with sizes of less than $15 \mu \mathrm{m}$ and 45-80 $\mu \mathrm{m}$ were advantageous for the 7- and 28-day compressive strength development of the concrete, especially at a low replacement ratio of up to $10 \%$. The concrete that was $5 \%$ and had $45-80 \mu \mathrm{m}$ particles presented the highest compressive strength at 7 and 28 days, which was $2 \%$ and $5 \%$ higher than the control concrete, respectively.

- Including the $45-80 \mu \mathrm{m}$ particles at $5 \%$ in the cement paste can result in a lower porosity and a finer pore structure than that in the cement paste at 28 days, thus contributing to the higher compressive strength development of the concrete. Combined with the TG analysis, these refined effects are also related to the pozzolanic activity of the $45-80 \mu \mathrm{m}$ steel slag particles, which consumed $\mathrm{CH}$ while producing additional C-S-H gels.

\section{REFERENCES}

1. Kovler K., Roussel N. (2011): Properties of fresh and hardened concrete. Cement and Concrete Research, 41, 775-792. doi: 10.1016/j.cemconres.2011.03.009

2. Nayak N. V. (2014). Recent Innovations in Concrete \& Foundations Leading Growth, Ed. http://slideplayer.com/ slide/4173867/.

3. Xu D., Cui Y., Li H., Yang K., Xu W., Chen Y. (2015): On the future of Chinese cement industry. Cement and Concrete Research, 78, 2-13. doi: 10.1016/j.cemconres.2015.06.012

4. Jiang Y., Ling T.-C., Shi C., Pan S.-Y. (2018): Characteristics of steel slags and their use in cement and concrete-A review. Resources Conservation and Recycling, 136, 187197. doi:10.1016/j.resconrec.2018.04.023

5. Pang B., Zhou Z., Xu H. (2015): Utilization of carbonated and granulated steel slag aggregate in concrete. Construction and Building Materials, 84, 454-467. doi: 10.1016/j.conbuildmat.2015.03.008

6. Shi Y., Chen H., Wang J., Feng Q. (2015): Preliminary investigation on the pozzolanic activity of superfine. Construction and Building Materials, 82, 227-234. doi: 10.1016/j.conbuildmat.2015.02.062

7. Ustabaş İ., Kaya A. (2018): Comparing the pozzolanic activity properties of obsidian to those of fly ash and blast furnace slag. Construction and Building Materials, 164, 297-307. doi: 10.1016/j.conbuildmat.2017.12.185
8. Tsakiridis P. E., Papadimitriou G. D., Tsivilis S., Koroneos C. (2008): Utilization of steel slag for Portland cement clinker production. Journal of Hazardous Materials, 152, 805-811. doi:10.1016/j.jhazmat.2007.07.093

9. Guo X. L., Shi H. S., Wu K. (2014): Effects of Steel Slag Powder on Workability and Durability of Concrete. Journal of Wuhan University of Technology, 29, 733-739. doi:10.1007/s11595-014-0988-2

10. Qasrawi H. (2014): The use of steel slag aggregate to enhance the mechanical properties of recycled aggregate concrete and retain the environment. Construction and Building Materials, 54, 298-304. doi: 10.1016/j.conbuildmat.2013.12.063

11. Rosales J., Cabrera M., Agrela F. (2017): Effect of stainless steel slag waste as a replacement for cement in mortars. Mechanical and statistical study. Construction and Building Materials, 142, 444-458. doi: 10.1016/j. conbuildmat.2017.03.082

12. Yu X., Tao Z., Song T.-Y., Pan Z. (2016): Performance of concrete made with steel slag and waste glass. Construction and Building Materials, 114, 737-746. doi:10.1016/j. conbuildmat.2016.03.217

13. Mladenovič A., Mirtič B., Meden A., Zalar Serjun V. (2016): Calcium aluminate rich secondary stainless steel slag as a supplementary cementitious material. Construction and Building Materials, 116, 216-225. doi: 10.1016/j. conbuildmat.2016.04.141

14. Xiang X.-d., Xi J.-c., Li C.-h., Jiang X.-w.(2016): Preparation and application of the cement-free steel slag cementitious material. Construction and Building Materials, 114, 874-879. doi: 10.1016/j.conbuildmat.2016.03.186

15. Shu C.-Y., Kuo W.-T. (2015): Expansion behavior of concrete containing different steel slag aggregate sizes under heat curing. Computers and Concrete, 16, 487-502. doi: 10.12989/cac.2015.16.3.487

16. Yang J., Lu J., Wu Q., Xia M. F., Li X. (2018): Influence of steel slag powders on the properties of MKPC. Construction and Building Materials, 159, 137-146. doi: 10.1016/j. conbuildmat.2017.10.081

17. Hu J. (2017): Comparison between the effects of superfine steel slag and superfine phosphorus slag on the longterm performances and durability of concrete. Journal of Thermal Analysis and Calorimetry, 128, 1251-1263. doi:10.1007/s10973-017-6107-9

18. Peng Y., Chen K., Hu S. (2011). Durability and Microstructure of Ultra-High Performance Concrete Having High Volume of Steel Slag Powder and Ultra-Fine Fly Ash, in: Zhao, J. Y. (Ed.): Advances in Civil Engineering. pp.452. doi:10.4028/www.scientific.net/AMR.255-260.452

19. Shi M., Wang Q., Zhou Z. (2015): Comparison of the properties between high-volume fly ash concrete and highvolume steel slag concrete under temperature matching curing condition. Construction and Building Materials, 98, 649-655. doi: 10.1016/j.conbuildmat.2015.08.134

20. Qiang W., Mengxiao S., Jun Y. (2016): Influence of classified steel slag with particle sizes smaller than $20 \mu \mathrm{m}$ on the properties of cement and concrete. Construction and Building Materials, 123, 601-610. doi: 10.1016/j.conbuildmat.2016.07.042

21. Zhao J., Wang D., Yan P., Zhang D., Wang H. (2016): Selfcementitious property of steel slag powder blended with gypsum. Construction andBuilding Materials, 113, 835-842. doi:10.1016/j.conbuildmat.2016.03.102 
22. Idir R., Cyr M., Tagnit-Hamou A. (2011): Pozzolanic properties of fine and coarse color-mixed glass cullet. Cement and Concrete Composites, 33, 19-29. doi:10.1016/j. cemconcomp.2010.09.013

23. Sun J., Xu K., Shi C., Ma J., Li W., Shen X. (2017): Influence of core/shell TiO2@SiO2 nanoparticles on cement hydration. Construction and Building Materials, 156, 114-122. doi: 10.1016/j.conbuildmat.2017.08.124

24. Qasrawi H., Shalabi F., Asi I. (2009): Use of low $\mathrm{CaO}$ unprocessed steel slag in concrete as fine aggregate. Construction and Building Materials, 23, 1118-1125. doi: 10.1016/j.conbuildmat.2008.06.003

25. Rehman S., Iqbal S., Ali A. (2018): Combined influence of glass powder and granular steel slag on fresh and mechanical properties of self-compacting concrete. Construction and Building Materials, 178, 153-160. doi: 10.1016/j.conbuildmat.2018.05.148
26. Zhang Y., Zhang Z., Li X., Li W., Shen X., Wang H. (2017): Effect of welan gum on the hydration and hardening of Portland cement. Journal of Thermal Analysis and Calorimetry, 131, 1277-1286. doi:10.1007/s10973-017-6589-5

27. Sun J., Shi H., Qian B., Xu Z., Li W., Shen X. (2017): Effects of synthetic C-S-H/PCE nanocomposites on early cement hydration. Construction and Building Materials, 140, 282-292. doi: 10.1016/j.conbuildmat.2017.02.075

28. Deschner F., Winnefeld F., Lothenbach B., Seufert S., Schwesig P., Dittrich S., Goetz-Neunhoeffer F., Neubauer J. (2012): Hydration of Portland cement with high replacement by siliceous fly ash. Cement and Concrete Research, 42, 1389-1400. doi:10.1016/j.cemconres.2012.06.009

29. Jeong Y., Park H., Jun Y., Jeong J.-H., Oh J. E. (2015): Microstructural verification of the strength performance of ternary blended cement systems with high volumes of fly ash and GGBFS. Construction and Building Materials, 95, 96-107. doi:10.1016/j.conbuildmat.2015.07.158 